\title{
La música tradicional venezolana: entrevista imaginaria realizada al concertista y compositor venezolano, Eladio Mujica
}

\author{
A Música Tradicional Venezuelana: Entrevista Imaginária Realizada com o concertista e \\ compositorvenezuelano Eladio Mujica \\ The Venezuelan Traditional Music: Imaginary Interview Performed with Venezuelan \\ composer and composer Eladio Mujica
}

Raimundo Mijares

\section{Resumen}

La siguiente entrevista imaginaria realizada al compositor y concertista venezolano, Profesor, Eladio Mujica la realicé en la ciudad de Caracas un día del mes de septiembre del año 2017. Fue un ejercicio que sirvió de pretexto para acercarme en el tiempo a un creador de la música venezolana. Recordando sus inicios en el repertorio de la guitara y el cuatro, el profesor Mujica ha significado una referencia de incalculable valor para el patrimonio musical de la música tradicional venezolana. Nuestra amistad se forjó en la ciudad de Porlamar cuando concurríamos al Complejo Cultural Modesta Bor en busca de conocimientos que lograsen colmar nuestras expectati- vas en las carreras que cada uno tenía en un horizonte no muy lejano. Nuestros pasos se separaron por aquellos años a finales de 1970 cuando Él, en el área de la música y mi persona en las artes del teatro y de regreso a Caracas, decido quedarme en la capital para desarrollar mi carrera en el ejercicio teatral, sin regresar por largo tiempo a la región espartana y sin enterarme certeramente de su paradero. No obstante, los caminos se juntan y precisamente en los actuales momentos, cuando una persona

Doutor em Patrimônio Cultural pela Ulac e docente da Universidad Latinoamericana y del Caribe/ Venezuela e Assessor Cultural da Universidad Simón Rodrigu. E-mail: raimundomijares@gmail.com

Recebido em 20/8/2017 - Aprovado em 21/9/2017 http://dx.doi.org/10.5335/hdtv.18n.1.7742 
amiga de ambos logra informarme de su persona, de lo que está haciendo y es en esos instantes cuando afloran aquellos recuerdos maravillosos de pretéritos años en tierras margariteñas, cuando juntos jugábamos a ser héroes. De esas añoranzas nace la disposición de realizar esta entrevista a mi amigo, enaltecida por el aprecio, admiración y respeto hacia la persona que es, Eladio Mujica. El tema de la entrevista escogido giró en torno a la música tradicional venezolana relacionándolo con los cuatro puntos cardinales de la geografía. Ese paneo por el pentagrama de la creación musical nacional es motivo de inspiración e identidad; demostrando la riqueza que reside, permanece y se expresa poniendo en evidencia la herencia y evolución histórica de cada una de esas expresiones.

Palabras claves: Diversidad musical. Entrevista imaginaria. Música tradicional venezolana. Patrimonio Cultural.

\section{Consideraciones iniciales}

Cuando tratamos de ubicar los orígenes de la música en Venezuela no es extraño que idéntica situación ocurra al intentar realizar un arqueo con otras formas culturales presentes a lo largo y ancho del territorio nacional.

De entrada es pertinente reconocer que lo que hoy día existe en instrumentación, así como en la fusión de sonidos que han venido definiendo lo "venezolano", importa en grado sumo las raíces aportadas por aborígenes, africanos y europeos. Por ello, ese largo proceso de dinámica cultural ocurri- do en las sociedades Estado-Nación donde la transculturación, entendida ésta como el transporte de cultura, la aculturación como la imposición de elementos culturales de un grupo social dominante a un grupo social dominado y la conculturación que define el libre intercambio de elementos culturales entre diferentes grupos sociales.

Pues bien, esos procesos culturales definieron esa riqueza musical que se fue construyendo en la dimensión geográfica de la colonia y la república, que una vez ocurrida el proceso de independencia continuó desarrollando ritmicidad, construyendo nuevos sonidos musicales identificados en la etnicidad y consustanciados con la venezolanidad. Es Venezuela en lo musical una inagotable fuente de sonidos y ritmos que apasionan y enorgullecen por sus ejemplares y creativas composiciones.

Estas formas musicales tal como el joropo, que devino en un proceso evolutivo hasta llegar a consustanciarse con la etnicidad presente en los llanos venezolanos, mientras otros géneros se hacen criollos conservando las huellas visibles de alguna de aquellas culturas matrices. Por eso, de acuerdo con las características mismas de su conformación, hoy día podemos distinguir varios tipos de música de nuestra tradición. En principio están aquellas de raíz aborigen , cultivadas en su contexto cultural o bien presentes en celebraciones del calendario religioso veniado de España, tal como Las Turas, donde se conservan rasgos que las distinguen como una forma musical de origen étnico americano. Asimismo, tenemos las de origen europeo que como el villancico o el aguinaldo, aclimatados hasta adquirir distintos ritmos criollos. También las que con- 
servaron la huella africana con sus ritmos, sus melodías y sus tambores.

La siguiente investigación de fuente documental cumple el pretexto de realizar una entrevista imaginaria. Subgénero al que los entendidos en el tema periodístico definen como un ejercicio intelectual para recrear un momento en particular sobre un hecho real o ficticio.

Se ha escrito de modo muy profuso acerca de la entrevista imaginaria, denominada así por su abordaje de un tema abierto al ensayo y a la profundización de las ideas, de modo que esta entrevista que le hago al profesor Eladio Mujica, separado por la distancia y la ubicación espacial (ya que desconozco donde se encuentra en los actuales momentos), tiene el propósito de reconocer el vasto talento musical de aquel joven margariteño quien en la década de 1970 descollaba su maestría en el manejo del cuatro y la guitarra. Hoy día, realizado en su manejo musical al frente de su cátedra musical y cumpliendo actividades en la gerencia cultural de su país.

Le recuerdo en su Nueva Esparta (Porlamar), cuando concurríamos al Complejo Cultural de Instrumentos de Cuerdas y Folclore Modesta Bor. Él a la Cátedra de Musicología y mi persona a las clases de teatro y títeres. Converso con él en el tiempo acerca de la música tradicional venezolana, desde la figura en la que convirtió el Maestro, Eladio Mujica, llenando de orgullo a su querida Nueva Esparta y a Venezuela toda.

\section{Eladio, ¿a qué edad comenzaste} con tu actividad como intérprete del cuatro? Yo me inicié con ese instrumento a la edad de nueve años.
¿Cuándo debutaste como concertista de ese instrumento? Eso ocurrió cuando yo tenía 15 años de edad y tuvo como marco una exposición del pintor venezolano, Octavio Russo en la ciudad de Porlamar.

Eladio, háblanos de la música venezolana, esa que reside en todos los puntos cardinales de la geografía venezolana. Mira, si hay en Venezuela una riqueza tangible, una de las más ricas sería la riqueza musical y que está disperso en todo el territorio de nuestro país. La música venezolana cuando queremos hablar de ella de manera general y haciéndole justicia también, se nos ocurre decir que si cuadriculáramos el país en cuadros de diez metros, en cada uno de esos cuadros la manifestación musical sería distinta. En algunos casos hay cierto parecido y en otros es radicalmente opuesto.

¿Podrías darnos un ejemplo de lo que dices? Pues, mira yo provengo de una isla, como tú sabes en el oriente venezolano, donde las manifestaciones musicales son muy características y que tienen un vínculo directo con la música española, en este caso, pues, con la música andaluza. De hecho, los nombres de los géneros musicales de mi pueblo están todos relacionados con la música andaluza. Hablamos de polos, malagueñas, puntos, fulías, galerones y jotas. Para que se evidencie con mayor crudeza creativa y diversidad, estos cantos que se hacen en la Isla de Margarita no tienen nada que ver con la música que se hace justo en frente de nuestra isla que es el estado Sucre.

¿Cómo se manifiestan estas diferencias? Mira, es muy difícil explicar esto, pero es radicalmente distinto. Pues, es el color musical, los instrumentos, las formas y los géneros son radicalmente distintos. Por supuesto, que es muy difícil explicar esto sin 
una muestra visual y auditiva de esta música. También hay que tomar en cuenta los cambios que ocurren en la música de acuerdo a las regiones donde se da el hecho musical.

¿Por ejemplo, que nos puedes decir del estado Zulia y música? Bueno, ese estado occidental de Venezuela se calcula que hay aproximadamente 140 géneros musicales, del mismo modo en la región de los Llanos. Los instrumentos radicalmente distintos, los géneros también, así como los ritmos, etc. Pero, en líneas generales, en la música tradicional venezolana hay dos caminos. Uno de esos caminos son los ritmos. Por ejemplo, existe una música como el bambuco que se toca en la región de Los Andes, que es un ritmo que se llama así por querer decir que melódicamente, armónicamente, el compositor tiene la libertad de hacer lo que desee, pero si el ritmo, en este caso la mano derecha con el cuatro, es ritmo de bambuco y aquella cosa por más osada y contemporánea que sea, pues, sigue siendo un bambuco. Y algo más, sigue siendo un bambuco tradicional. Por ello nos referimos al ritmo. Y así como existe la gaita zuliana que es una cosa totalmente libre que está amarrada a una situación y un ritmo. El ritmo de gaita, que en este caso es un ritmo expresado en seis octavas, es decir $(6 \times 8)$, que se interpreta con unos acentos particulares y que hacen que todo lo que suene en ese ritmo los zulianos lo clasifican como gaita. La gaita zuliana.También es importante saber que esa gaita se toca en la región zuliana, ya que sería muy exótico encontrar gaita zuliana en otros estados venezolanos. A menos que por factores de migración y/o presentaciones por contratación se vean estas interpretaciones fuera del territorio zuliano.
Una pregunta, profesor Mujica, ¿es difícil hablar de música venezolana? No, no lo es. Sin embargo, te digo que no se puede hablar de la música venezolana sin referirse a la poesía venezolana. ¿Por qué lo dices? Bueno, porque la música está presente en las palabras cuando les colocamos música, Hay algunos géneros que sería imposible de hacer sin el canto, pero se dan cosas muy particulares. Un ejemplo de ello lo tenemos en la región zuliana donde existe el género de monoy (palabra hebrea), que consiste en una estructura armónica fija que se repite donde un cantador improvisa una melodía. Por ejemplo, el polo margariteño es una estructura armónica que se repite. De modo que cuando tenemos esas estructuras armónicas hablamos de géneros. En tal sentido existen muchos géneros en la música tradicional venezolana. Difícilmente podría hablarte de todos los géneros en esta entrevista, pero sí referirme a algunos de ellos. Está el caso de un canto de mi pueblo que es un canto propio de allí, es un canto endémico, que se llama el punto, el punto del navegante.

Eladio, ¿puedes hablarnos de lo que significa el punto como género musical?

Sí, claro que sí. Por cierto tenemos el punto del navegante y así también en otros lugares de Venezuela existen puntos de velorio, el cual esun canto más propio de leñadores, pero sin embargo en mi pueblo, es un canto de marineros.

¿Cuáles son los géneros más comunes en la música tradicional? Entre ellos tenemos que hablar del vals que es muy querido y apreciado, tanto es así que la generalidad de los compositores venezolanos han escrito valses. Por ejemplo los valses del Maestro, Antonio Lauro para guitarra son verdaderas joyas musicales. Luego está el merengue ve- 
nezolano que es una composición que no tiene ninguna empatía con el merengue dominicano que es una música bailable. Esta es una música tradicional caraqueña que gira en torno a la retreta. Que está vinculado con la capital de Venezuela. La música tradicional caraqueña gira en torno a este merengue, que es una melodía que se escribe en un ritmo de cinco octavo $(5 / 8)$ y por tradición lo escriben en dos sobre cuatro que obviamente está mal hecho, ya que cuando en dos sobre cuatro es muy difícil que un europeo pueda entender la verdadera esencia de este ritmo. También es de observar que a este merengue tradicional caraqueño se le llama rucaneao que es un merengue que tiene un sabor muy particular y que hay aprenderlo a tocar y su particularidad es que se aprende a bailar con la convivencia, con la gente que lo toca.

Profesor Eladio Mujica, ¿cuán diverso es el universo de la música tradicional venezolana? Pues, te digo lo siguiente: comenzando por el oriente que es la región noroeste, el noroeste que es la región occidental y los llanos al sur y la región de los andes. Cada una de esas regiones son mundos musicales insólitamente distintos. Es impensables para nosotros tener una persona de Margarita y pretender que pueda cantar como lo pudiese hacer un andino o viceversa. Esas diferencias y diversidades nos hacer ser un país realmente diverso en el aspecto musical. También quiero referirme en esta entrevista a la poesía, porque existe un género musical en el estado Zulia que es la décima zuliana. Esto es un caso particular en nuestra música porque se sabe que la décima es un género literario que proviene de España que se trata de y/o se compone de diez versos en octosílabos con rima ri- gurosa, que se le atribuye al señor Vicente Spinelli, la décima Spinelli.

Profesor Mujica, ¿cómo se canta la décima en la Isla de Margarita? La décima se canta de muy diversas maneras, se canta como galerón, como gaita, como punto, pero se utiliza la estructura Spinella. Pero en el Zulia es un tanto diferente, allí es un género musical. Partamos de cómo se hace la décima en el oriente de Venezuela. Allí uno de los cantos más representativos es el polo margariteño. Este género se estructura en cuartetas, lo que llamamos coplas. El canto sigue siendo el mismo con cantos entrecruzados. Es de señalar que en estos cantos hay una cadencia andaluza., ya que la herencia de la conquista española está presente en esos cantos a través de los nombres de los géneros y la cadencia musical.

Profesor Mujica, ¿estos cantos aluden a una particularidad? Sí, estos cantos están enfocados en situaciones particulares. El polo es una canción que se hace cuando llega una visita a la casa y que por alguna razón quiere molestar a alguien de la vivienda, entonces canta un polo. Los polos tradicionalmente no son poéticos, no suelen ser poéticos. En vista de ello, cada canto está dirigido a una cosa en particular. Por ejemplo en el canto a la Cruz de Mayo se le canta galerones que alude a las lluvias, a la abundancia, al compartir. En el caso del polo en la Isla de Margarita hay una interpretación que es muy sonora, bastante alegre, que es realizada por las personas que residen cerca de la costa y otra más tranquila y apaciguada que las hacen las personas que residen en las montañas o lugares alejados del mar.

¿Cómo se canta las coplas en forma de polos? Bueno, tenemos la malagueña que es un canto poético en tono mayor que modula 
hacia abajo y hacia arriba. El punto del navegante es uno de los géneros más endémicos que tenemos los margariteños, el más sentido en Venezuela. El punto es lo que para nosotros en la música académica sería un canto sacro. Es uno de los géneros pocos conocidos en Venezuela. Sin embargo es uno de los más sentidos. Alude con su canto la pérdida de un ser querido, la pérdida de algo muy preciado para la persona. También es interesante hablar de la gaita margariteña, y que al igual que en España y el Zulia, esta de la Isla de Margarita es un género musical que utiliza la décima Spinnelli como estructura poética y tradicionalmente se improvisa.

¿También tienen música para homenajear a las niñas cuando celebran sus $\mathbf{1 5}$ años? Sí, por supuesto en la Isla de Margarita existe un género musical que se llama la sábana blanca. Su canto consiste en una serenata que alude a la pureza y la pureza de la niña. Este canto son coplas que se improvisan. El cantador debe recordar lo que ha improvisado y luego cantar el verso al revés conservando la rima. Luego tenemos otro género que se llama el estribillo; de hecho existen tres tipos de estribillo. Uno es el estribillo margariteño, el otro es sucrense y uno estándar. Esta el caso del estribillo sucrense que es muy hermoso musicalmente y propio de su zona, no así en los estados Monagas y Anzoátegui que por tener una cercanía con los llanos no desarrollaron una música propia identitaria que les de identidad musical.

Bueno, profesor Mujica iahora nos mudamos al estado Sucre para hablar de su música? Sí, efectivamente en el estado Sucre tenemos el punto de velorio que se canta en el mes de mayo para celebrar la Cruz de Mayo. También es el canto de apertura para el galerón. En el punto se alarga el canto porque los cantadores quieren dejar referencia de su presencia en las celebraciones. También es oportuno referirse a la jota; como un vínculo que se tiene con la tradición española a través de Andalucía. En el estado Sucre es común escuchar la jota oriental tradicional y la jota carupanera. Es un tanto extraño este género porque no hs sido estudiada y tampoco se enseña en los conservatorios, sin embargo es muy popular y requiere de habilidades musicales extraordinarias para su ejecución.

Profesor Mujica, nos encontramos en el estado Zulia para hablar de su hermosa música. Dentro de la variadísima y rica música zuliana hablemos de la gaita de tambora que es la más conocida y difundida, así como la gaita perijanera y la gaita de churro. También está la música de los pueblos de agua que es la gente que vive en los palafitos. Son comunidades aborígenes que han permanecido en sus hábitats por centenares de años y han erigido una música muy particular.

Profesor Mujica nos trasladamos al estado Mérida para escucharlo hablar de la belleza musical de esa región. Sí, en efecto. Vamos a observar cómo la musicalidad, los instrumentos, las letras de sus canciones son todas distintas. La manifestación tradicional musical por excelencia de los andes es el bambuco. Es una danza lenta que sirve como pretexto para cantar las cosas más hermosas que se han escrito en Venezuela. El compositor por excelencia de los bambucos lo fue el compositor sucrense, Luis Mariano Ramón y Rivera. Sin embargo. Está también la figura del compositor aragüeño, Henri Martínez quien ha venido componiendo 
bambucos como una forma de ofrecer excelentes composiciones de ese género musical.

Ahora nos encontramos con la música del llano venezolano. Allí nos vamos a encontrar con el pasaje, joropo, el pajarillo, el zumba que zumba, el corrío o corrido. Son géneros musicales sencillos y muy hermosos. Nosotros tenemos la presencia poética de un gran llanero como lo fue, Alberto Arvelo Torrealba, quien es el autor de una leyenda muy famosa denominada Florentino y el Diablo.

También tenemos la presencia de un género musical que se conoce como la gaita antillana. No tienen ningún parecida con la gaita zuliana ni con la margariteña. Esta viene de Cuba. Su cometido es causar algún impacto molesto en quienes escuchan estas composiciones.

Casi concluimos esta entrevista imaginaria refiriéndonos a la música del centro de Venezuela cuyo origen es muy compleja porque en la región central, específicamente en los estados Miranda y Aragua el instrumento que floreció allí fue el clavecín. Allí ocurrió algo muy particular y es que los lugareños del lugar convirtieron ese instrumento en un arpa con cuerdas de metal, dando lugar al surgimiento de una música muy particular donde no existe el cuatro. Es la única región de Venezuela donde el cuatro no participa en los ensambles grupales. Es una música campesina con muchas particularidades. Los joropos tuyeros reciben esta denominación por la toponimia del lugar que tiene un río que atraviesa la zona que se llama Río Tuy. La características de sus temas se refieren a la improvisación sobre lo que ocurre en los lugares donde tienen su desarrollo las fiestas. Su instrumentación consiste en arpa y maracas.

Finalmente, tenemos es estado Lara donde también se hace una música muy rica en sonoridad que es el golpe larense. Asimismo, está el tamunangue que es como una suite, un compendio de varias danzas. Este estado se le reconoce como la capital musical de Venezuela, ya que allí han nacido, Rodrigo Riera, Alirio Díaz, Gustavo Dudamel y el Maestro Carrillo.

\section{Resumo}

A seguinte entrevista imaginária feita com compositor e artista venezuelano, Professor Eladio Mujica, eu a executei na cidade de Caracas em um dia em setembro de 2017. Foi um exercício que serviu de pretexto para se aproximar no tempo a um criador da música venezuelana. Recordando seus começos no repertório de guitarra e cuarto, o professor Mujica significou uma referência de valor incalculável para a herança musical da música tradicional venezuelana. Nossa amizade foi forjada na cidade de Porlamar quando fomos ao Complexo Cultural Modesta Bor em busca de conhecimento que conseguiu cumprir nossas expectativas nas carreiras que cada uma tinha em um horizonte não muito distante. Nossos passos se separaram naqueles anos no final da década de 1970, quando ele, na área de música e minha pessoa, nas artes do teatro e de volta a Caracas, decidi permanecer na capital para desenvolver minha carreira no teatro, sem retornar por um longo tempo para a região espartana e sem saber com certeza o seu paradeiro. No entanto, as estradas 
se juntam e precisamente no momento presente, quando uma pessoa que é amiga de ambas consegue me informar sobre sua pessoa, o que está fazendo e é nesses momentos em que essas maravilhosas lembranças de anos passados nas terras de Margarite se juntam quando jogamos para ser heróis. A partir desse anseio vem a provisão desta entrevista ao meu amigo, exaltada pela apreciação, admiração e respeito pela pessoa que é, Eladio Mujica. O tema da entrevista escolhida girava em torno da música venezuelana tradicional, relacionando-a aos quatro pontos cardinais da geografia. Esta panorâmica para a equipe nacional de criação musical é fonte de inspiração e identidade; demonstrando a riqueza que reside, permanece e se expressa ao destacar o patrimônio e a evolução histórica de cada uma dessas expressões.

Palavras-chave: Diversidade musical. Entrevista imaginária. Música venezuelana tradicional. Patrimônio cultural.

\section{Abstract}

The following imaginary interview made with the Venezuelan composer and performer, Professor Eladio Mujica, was performed in the city of Caracas one day in September of 2017. It was an exercise that served as a pretext to approach in time a creator of the Venezuelan music. Recalling his beginnings in the repertoire of guitar and cuatro, Professor Mujica has meant a reference of incalculable value for the musical heritage of Venezuelan traditional music. Our friendship was forged in the city of Porlamar when we went to the Modesta Bor Cultural Complex in search of knowledge that managed to fulfill our expectations in the careers that each had in a not too distant horizon. Our steps separated in those years in the late 1970s when he, in the area of music and my person in the theater arts and back to Caracas, decided to stay in the capital to develop my career in theater, without returning for a long time to the Spartan region and without knowing for sure of his whereabouts. Nevertheless, the roads come together and precisely at the present moment, when a person who is friends of both manages to inform me of his person, of what he is doing and it is in those moments when those marvelous memories of past years of Margarite land arise, when together we played to be heroes. From these longings comes the provision of this interview to my friend, extolled by the appreciation, admiration and respect for the person who is, Eladio Mujica. The theme of the chosen interview revolved around traditional Venezuelan music, relating it to the four cardinal points of geography. This panning for the national musical creation staff is a source of inspiration and identity; demonstrating the wealth that resides, remains and is expressed by highlighting the heritage and historical evolution of each of these expressions.

Keywords: Cultural heritage. Imaginary Interview. Musical diversity. Traditional Venezuelan music. 